\title{
Making a case for life
}

Exhibits at the Natural History Museum in London, such as these models of rat fleas on show in 1927, have been drawing the crowds since the museum opened its doors in 1881. This exhibit was part of a campaign to inform the public of the role of insects in spreading disease.

Photographers, both professional and amateur, have recorded events in the life of 'the world's greatest cathedral to natural history', which has amassed a collection of more than 6,000 images. As well as showing the public face of the museum, the collection contains many pictures showing the minutiae of daily life behind the scenes, as the staff worked to conserve and prepare the exhibits. Arrivals and departures of famous specimens such as the blue whale are recorded, with the style of exhibits changing along with the hairstyles and dress of visitors and staff.

About 100 of these images are themselves now on show, in an exhibition that runs until 20 February 2004 and in a book, Life Through a Lens by Susan Snell and Polly Tucker (Natural History Museum Publishing, £15).

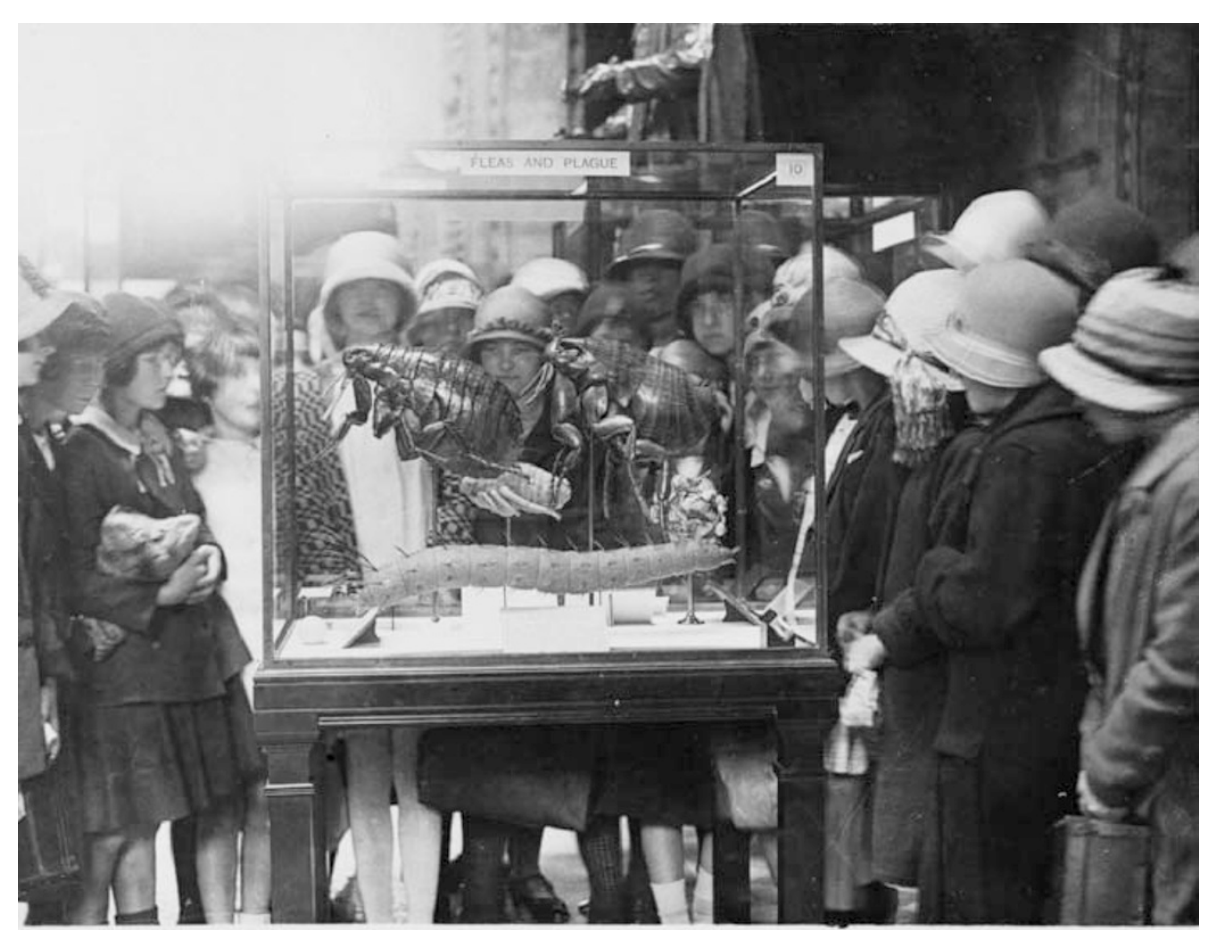

about the past does not necessarily point the way to future action, but it can serve as an important corrective to misperceptions about the past, which have frequently led to policy-making based on ideology rather than reality.

Gerald N. Grob is emeritus professor at the Institute for Health, Health Care Policy, and Aging Research, Rutgers University, 30 College Avenue, New Brunswick, New Jersey 08901, USA.

\section{Core research}

\section{The Dynamic Structure of the Deep Earth: An Interdisciplinary Approach}

by Shun-ichiro Karato

Princeton University Press: 2003. 264 pp.

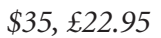

\section{Quentin Williams}

The deep interior of the Earth is, like space, a seemingly endless source of inspiration for popular fiction. A recent movie, The Core, followed this tried-and-tested theme with a tale of travel to the centre of the planet. Along the way, a predictable sequence of characters must die (with their order of demise apparently determined by development, ethnicity, nationality and personality) to ensure that the outrageously attractive protagonists survive to return to the surface.

The realities associated with the deep Earth are actually far more interesting than one might guess from Hollywood's formulaic prosaism. The deep Earth manufactures diamonds and delivers them, uncombusted, to Earth's surface. Its degassing probably furnished us with Earth's surface water and the starting materials for our atmosphere. And it provides the engine for plate tectonics - the source of mountains, ocean basins and almost everything in between.

Our understanding of Earth's interior has mushroomed over the past two decades, driven by a synergy between improved seismic imaging, better understanding of the properties of Earth's materials at extreme pressures and temperatures, and computationally intensive simulations of the planet's interior.

The author of The Dynamic Structure of the Deep Earth, Shun-ichiro Karato, was trained in rock mechanics and has worked on a broad range of deep-Earth related topics, so he is well equipped to write such a book. Its intent, as outlined in the preface, is not to provide a synopsis, but rather to introduce the interdisciplinary approach of the subtitle through specific problems on which the author has worked. The book seems to belong to a fine tradition of volumes about the deep Earth that incorporate general introductions to research areas but also serve to revisit and remind people of the (mostly already published) viewpoints of the author.

This style perhaps reached its apex with A. E. Ringwood's Origin of the Earth and Moon (Springer, 1979), which both placed Ringwood's views into a tutorial framework and provided a focal point for scientific disagreements. This is a lofty benchmark, and the ultimate success of Karato's book will be determined by the long-term importance and longevity of the views described.

The topics of the book span the depth range of the planet, from the boundary between the rigid outer lithosphere and the underlying fluid asthenosphere to the inner core. The introductory chapter is one of the highlights of the book - a nice pedagogic overview of Earth's structure, complete with boxes containing derivations of the relevant parameters. The author then provides reviews and gives his own take on a selection of current deep-Earth research problems. These include discussions of the lithosphereasthenosphere boundary and the origin of the 'low-velocity zone' within the shallow upper mantle; the meaning of seismically fast and slow zones in tomographic models of Earth's interior; the relationship between

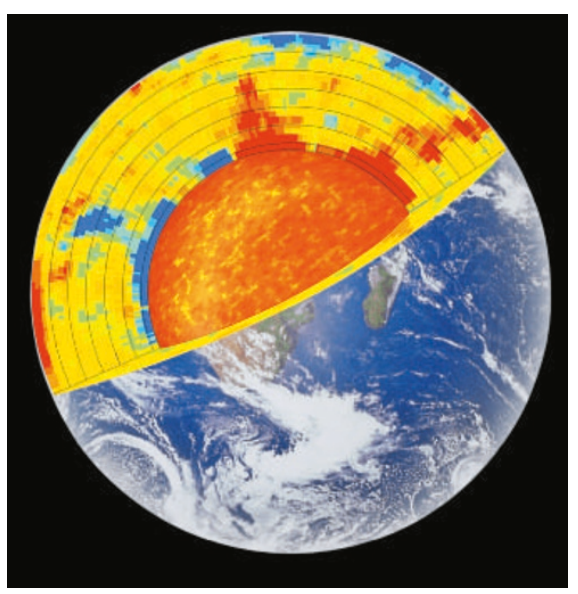

The rise and fall of slabs of hot (red) and cold (blue) rock in the mantle drives plate tectonics. 


\section{Luminet's illuminations}

\section{Cosmological modelling and the art of intuition.}

\section{Martin Kemp}

Letters to Nature do not usually open with a peroration on musical harmonics and the organization of the Universe. But Jean-Pierre Luminet, the lead author of a recent paper on the topology of the Universe (Nature 425, 593-595; 2003), is no ordinary scientist - at least by today's standards. In some ways, he seems to belong more to the era of Johannes Kepler and his Renaissance predecessors.

Already an advocate of finite models as solutions to cosmological conundrums, he now joins with his colleagues in using measurements of microwave-background temperature fluctuations from the Wilkinson Microwave Anisotropy Probe to propose a model of a finite Universe based on Poincaré dodecahedral space, as already envisaged in Luminet's book L'Univers Chiffonné (Fayard, 2001). To convey their vision, they illustrate a beguiling sphere of curved pentagons and a dense view through the surface of a hypersphere tiled with 120 spherical dodecahedra.

To me, a visual historian, the images feel like coming home. After the puzzling 'brane worlds' of Stephen Hawking and others (see Nature 415, 738; 2002), we are now only a few multidimensional steps from the model of the cosmos in Kepler's Mysterium Cosmographicum (1596), which involves a spherical inscription and concentric nesting and the five regular polyhedra (see Nature 393, 123; 1998). Luminet's reinstated visualization of a finite Universe, albeit one from which we can exit through one face and simultaneously enter through the opposite one, relies upon a keplerian form of mental sculpture that may be described as plastic rather than algebraic.

It is not a great surprise to find that Luminet is a co-author, with Marc Lachièzé-Rey, of Celestial Treasury: From the Music of the Spheres to the Conquest of Space (Cambridge University Press,

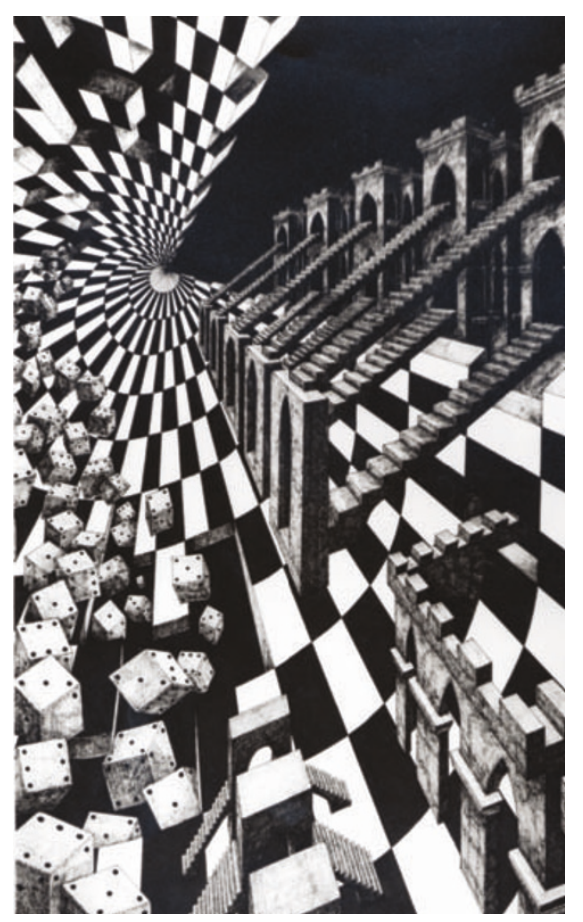

Jean-Pierre Luminet's Big Bang combines science and art in a multidimensional view of space.

2001), in which such Renaissance luminaries as Kepler and the German artist Albrecht Dürer are given their due. More unexpected are Luminet's activities as an artist and as a published poet. Moreover, he has collaborated with the composer Gérard Grisey on a piece of cosmic music, Le Noir de l'Etoile.

Luminet's characteristic lithograph, Big Bang, shown here, exploits the spatial vocabulary of perspective to evoke realms beyond the three dimensional. Whereas Escher relied on contradictions and oscillating ambiguity in his graphic art, Luminet suggests plunging, interpenetrating and vertiginous illogicalities of dynamic space. Spewing from the Big Bang in the top left-hand corner, matter organizes itself into structures on the right; the tumbling dice on the left imply irreversible disorganization arising from chance.

The remarkable range of Luminet's creativity in art and science is integral to his agenda to recreate what he calls a "humanism of knowledge" - not that the arts and sciences are somehow to be conflated, because they work in very different ways, with illogical and logical means. But Luminet argues that they well up from the same instincts and intuitions: "I do not believe that we acquire at the beginning the 'heart of an artist' or the 'heart of a scientist'. There is simply within oneself a single devouring curiosity about the world. This curiosity pushes us to explore it through various languages and modes of expression," he says.

Like science, the arts have developed some fundamental rules: poets have established a series of set forms, for example; painters have pursued variations on perspective; and musicians have developed a harmonic language that is at once simple and intricate. The modes of formal organization have varied over time, yet a work of art habitually relies on tension between set structure and unpredictable freedom, regardless of the kind of formal organization used.

Luminet has the courage to acknowledge the passionate engagement that potentially flows undetected beneath the dry crust of the standard scientific paper. He asks: "Why do we want to separate knowledge from emotion?" His answer is that "amazement about the world is the common root", which is expressed through a "harmonious integration" of all those intellectual and creative faculties that we use to respond to the wonder of things, both immense and minute.

Martin Kemp is professor of the history of art at the University of Oxford and co-director of Wallace Kemp/Artakt. seismic anisotropy of the mantle and mantleflow patterns; the rheology of subducted slabs and their geochemical consequences; and possible models for the physical origin of deep earthquakes.

The book concludes with a chapter on core formation, magnetic-field generation and the inner core. This ball of iron at the centre of the Earth has been shown over the past 20 years to have some unusual properties: seismic waves travel faster parallel to the rotational axis than along equatorial paths, and it might (or might not) rotate at a slightly faster rate than the rest of the Earth. The author's own ideas on the origin of anisotropy in the inner core through magnetic-field-induced stresses are described in a somewhat muted way here, leading to a more balanced feel. The book thus provides a sampler of deep-Earth problems. And as with most samplers, different readers will find nuggets that they like, and others of which they are not so fond.

The key point that emerges, irrespective of the precise flavour of each chapter, is that profound issues of planetary importance about the deep Earth remain unsolved. Conveying this fact achieves a portion of the author's intent in writing this book.

This book was originally published in 2000 in Japanese. This English translation has been substantially updated, but unfortunately the translation is sometimes distracting - some awkward sentences interfere with the flow of the text. Also, a few colour figures would have been worth the invest- ment — I'd forgotten how horrid seismic tomography looks in shades of grey.

Even with these cosmetic flaws, the book will be of value to practitioners of the deepEarth sciences. Particularly useful are its handy tutorial derivations of a broad range of simple mathematical concepts, and its reviews of some provocative current topics. I would recommend the book to advanced undergraduates, new graduate students or deep-Earth neophytes, if they are equipped with plenty of complementary reading and are already endowed with what we hope our students develop - a sceptical eye for the deep-Earth guy.

Quentin Williams is in the Department of Earth Sciences, University of California, Santa Cruz, California 95064, USA. 